\title{
Machine perfusion for improving outcomes following renal transplant: current perspectives
}

This article was published in the following Dove Press journal:

Transplant Research and Risk Management

29 March 2016

Number of times this article has been viewed

\author{
Robert M Cannon' \\ Glen A Franklin ${ }^{1,2}$ \\ 'The Hiram C Polk Jr MD Department \\ of Surgery, University of Louisville, \\ ${ }^{2}$ Kentucky Organ Donor Affiliates, \\ Louisville, KY, USA
}

\begin{abstract}
There is a disparity between the number of kidneys available for transplantation and the number of patients awaiting an organ while on dialysis. The current kidney waiting list in the US contains more than 100,000 patients. This need has led to the inclusion of older donors with worsening renal function, as well as greater utilization of kidneys from non-heartbeating (donation after cardiac death) donors. Coinciding with this trend has been a growing interest in technology to improve the function of these more marginal organs, the most important of which currently is machine perfusion (MP) of donated kidneys after procurement. While this technology has no standard guidelines currently for comprehensive use, there are many studies that demonstrate higher organ yield and function after a period of MP. Particularly with the older donor and during donation after cardiac death cases, MP may offer some significant benefits. This manuscript reviews all of the current literature regarding MP and its role in renal transplantation. We will discuss both the experience in Europe and the US using machine perfusion for donated kidneys.
\end{abstract}

Keywords: machine perfusion, renal transplantation, kidney pumping, renal failure, organ donation

\section{Introduction}

With the wide gap between the number of patients in need of a kidney transplant and the availability of kidneys for transplantation, transplant programs worldwide have faced the need to pursue organs from increasingly marginal donors in order to expand the availability of this lifesaving procedure to a greater proportion of the waiting list. Currently, there are more than 100,000 people in need of a renal transplant in the US. This need has led to the inclusion of older donors with worse renal function, as well as greater utilization of kidneys from non-heartbeating (donation after cardiac death [DCD]) donors. Coinciding with this trend has been a growing interest in technology to improve the function of these more marginal organs, the most important of which currently is machine perfusion (MP) of donated kidneys after procurement.

The concept of MP of donated kidneys is not a new one. Early research into MP dates back to the 1960s. ${ }^{1,2}$ The first clinical application MP to donor kidneys came from Belzer's group in 1968, in which a kidney was successfully transplanted after a 17-hour preservation period. ${ }^{3}$ With the introduction of effective static cold storage (CS) solutions and the acceptance of donation after brain death, however, MP subsequently declined in the 1980s and 1990s. While static CS remains the most common method for kidney preservation, ${ }^{4}$ there has been a resurgence of interest in MP as investigators have discovered numerous benefits associated with MP. Between 2007 and 2012, there 
was a 37\% increase in MP utilization for kidneys transplanted in the US. ${ }^{5}$ MP now plays a useful diagnostic role in determining which kidneys will be viable for transplantation, and has been shown in the majority of the available evidence to improve early graft function. ${ }^{6,7}$ Future areas of research with the potential to further improve outcomes include normothermic perfusion, oxygenation of the perfusion circuit, and addition of additional molecules to the perfusion solution in an effort to not just preserve, but to actually resuscitate kidneys prior to transplantation. This review will serve to highlight the current clinical applications and utility of MP to kidney transplantation, and identify directions for future expansion and refinement in the technology of MP.

\section{Improvement in clinical outcomes with MP}

The most important evidence for the benefit of MP in kidney transplant outcomes came in 2009 with the publication of the multicenter prospective randomized Eurotransplant trial. ${ }^{8}$ In this study, 672 paired deceased donor kidneys (336 donors) were randomized to undergo either MP or static CS. The pumped group of kidneys were placed on the LifePort Kidney Transporter (Organ Recovery Systems, Itasca, IL USA) immediately after procurement and remained on the pump for the duration of preservation. The perfusion system utilized pulsatile flow at a temperature of $1^{\circ} \mathrm{C}-8^{\circ} \mathrm{C}$ without oxygenation. Delayed graft function (DGF) occurred in $26.5 \%$ of static CS kidneys compared to only $20.8 \%$ of the MP kidneys, which translates to a 0.57 odds ratio (OR) for DGF in the MP group $(P=0.01)$. The magnitude of reduction in DGF was similar when standard criteria donors (SCD), extended criteria donors (ECD), and DCD donors were analyzed separately. For the kidneys that did develop DGF, the duration was significantly shorter in the MP group (10 vs 13 days; $P=0.04)$. In addition to a reduction in DGF, MP was also shown to improve 1 year graft survival (94\% vs $90 \%$; $P=0.04$ ) compared to $\mathrm{CS}^{8}$

One of the potential limitations of the Eurotransplant study was its potential wide applicability, in that kidneys randomized to MP were immediately perfused with a transportable MP apparatus. In practice in the US, many organs undergo a period of static CS prior to undergoing MP when they are transferred to the home organ procurement organization. In order to determine outcomes with the utilization of MP in the US, our group performed an analysis based on nationwide United Network for Organ Sharing (UNOS) data in which 13,293 deceased donor kidneys undergoing MP were compared to a propensity matched cohort of 13,293 kidneys undergoing CS alone. As was seen in the Eurotransplant trial, MP significantly decreased the incidence of DGF versus CS alone (19.7\% vs $27.5 \% ; P<0.001)$. On multivariable analysis, utilization of MP was the second strongest predictor of DGF (OR $0.63 ; P<0.001$ ) following DCD. Graft survival was not significantly different in the two arms of this study. ${ }^{9}$

In the authors' study, ${ }^{9}$ we noted that the utilization of MP was biased toward more marginal donors, with $52.6 \%$ of MP kidneys coming from either ECD or DCD donors. The role of MP in improving early outcomes with ECD kidneys has been supported by multiple studies. ${ }^{10-14}$ In a study of the US Renal Data System from 1995 to 2004, Buchanan et al ${ }^{10}$ demonstrated a reduction in DGF rates from $38 \%$ with CS to $27 \%(P<0.001)$ with MP. Furthermore, recipients of MP kidneys in this study had transplant hospitalization costs that averaged US\$2,131 less than their counterparts receiving CS kidneys. In a subgroup analysis of the ECD kidneys in the Eurotransplant trial, Treckmann et $\mathrm{al}^{11}$ demonstrated a reduction in DGF from $29.7 \%$ in the CS group compared to $22 \%$ in the MP group (OR $0.46 ; P=0.047$ ). Primary nonfunction was also significantly lower in the MP group (3\%) compared to the CS group $(12 \% ; P=0.04)$. As seen in the larger trial cohort, 1 year graft survival was significantly improved with the utilization of MP $(92.3 \%$ vs $80.2 \% ; P=0.02)$.

With regard to the utility of MP for DCD donors, the currently available data present a more mixed picture. ${ }^{15-20}$ In a 2010 randomized controlled trial performed in the UK, kidneys from 45 DCD donors (90 kidneys total) were randomized to either MP or CS alone. The incidence of DGF was similar in the MP (58\%) and CS (56\%) groups. The trial had planned to include at least 142 patients, although the nonsignificant benefit of MP in analysis of initial cohort of randomized patients led to early cessation of the study for reasons of futility. ${ }^{21}$ In contrast Jochmans et al $^{22}$ examined 82 kidney pairs from DCD donors in an extension of the Eurotransplant study. MP in this study reduced DGF from $69.5 \%$ to $53.7 \%$ (OR $0.43 ; P=0.025$ ). MP did not have a significant effect on graft survival in this study. Table 1 summarizes the outcomes involving the use of MP in these studies.

While the majority of the literature focuses on the benefit of applying MP to marginal kidney donors, there is growing evidence that it is equally beneficial when used for lower risk donors. In a single center paired kidney study in which $95 \%$ of all donors were categorized as SCD, Shah et $\mathrm{al}^{23}$ demonstrated reduction in DGF from 35\% with CS alone to $5 \%$ with MP $(P<0.01)$. As noted previously, the prospective randomized Eurotransplant trial did not find a difference in the magnitude of MP benefit when donors were stratified by 
Table I Summary of major publications regarding outcomes from machine perfusion

\begin{tabular}{|c|c|c|c|c|c|}
\hline Trial & Machine perfusion & Donor type & Number of kidneys & Machine device & $\begin{array}{l}\text { Percent kidneys } \\
\text { with DGF (\%) }\end{array}$ \\
\hline \multirow[t]{2}{*}{ Moers et a ${ }^{8}$} & Yes & All & 336 & LifePort & 20.8 \\
\hline & No & All & 336 & - & 26.5 \\
\hline \multirow[t]{2}{*}{ Cannon et $\mathrm{al}^{9}$} & Yes & All & 13,293 & Multiple & 19.7 \\
\hline & No & All & 13,293 & - & 27.5 \\
\hline \multirow[t]{2}{*}{ Treckmann et al" } & Yes & ECD & 91 & LifePort & 29.7 \\
\hline & No & ECD & 91 & - & 22 \\
\hline \multirow[t]{2}{*}{ Watson et $\mathrm{al}^{21}$} & Yes & DCD & 45 & LifePort & 58 \\
\hline & No & $\mathrm{DCD}$ & 45 & - & 56 \\
\hline \multirow[t]{2}{*}{ Jochmans et $\mathrm{a}^{22}$} & Yes & DCD & 82 & LifePort & 69.5 \\
\hline & No & DCD & 82 & - & 53.7 \\
\hline
\end{tabular}

Abbreviations: DGF, delayed graft function; ECD, extended criteria donors; DCD, donation after cardiac death.

risk category. ${ }^{8}$ Our group has recently performed a subgroup analysis of UNOS data regarding the utility of MP in SCD donors. In analysis of 9,882 MP kidneys compared to a propensity matched cohort of CS kidneys, DGF was reduced from $25.3 \%$ to $16.8 \%$ (OR $0.59 ; P<0.001) .{ }^{24}$ This study found a significant benefit of MP utilization outside the traditional realm of marginal donor kidneys.

The two current most commonly utilized MP systems are the LifePort (Organ Recovery Systems, Figure 1A) and RM3 (Waters Medical Systems, Rochester, MN, USA) devices (Figure 1B). The primary difference between the two machines is that the LifePort system is pressure driven, while the RM3 system is flow driven. Both machines have demonstrated superior outcomes to CS alone; however, the superiority of one machine over the other remains a matter of debate. While the body of evidence is limited, a recent randomized controlled trial of 50 kidneys obtained from 25 donors demonstrated similar DGF rates (32\%) in both groups. The duration of DGF, however, was significantly shorter in the LifePort group. Patients with DGF in the LifePort group required a mean of 2.65 dialysis sessions compared to 4.66 sessions in the RM3 group $(P=0.005)$. Furthermore, interstitial fibrosis and tubular atrophy were significantly more common in the RM3 group. The authors hypothesize that the LifePort system offers better endothelial protection through its ability to produce similar flows at a lower perfusion pressure. ${ }^{25}$

The optimal duration of MP is also a question that remains to be answered. In a paired kidney study, Ciancio et $\mathrm{al}^{26}$ compared a group of kidneys with a mean pump time of 22.7 hours with a group of kidneys with a mean pump time of 31.2 hours. By nature of the study design, all donor factors in the two groups were identical. Despite a significantly longer pump time in one group, there was no statistical difference in DGF rates between the two groups, suggesting that longer pump times do not lead to worse outcomes. Thus, while longer pump times do not appear to be harmful, there is still the question as to whether a minimum time on pump is needed to see any benefit. Patel et $\mathrm{al}^{27}$ have shown that renal arterial resistance continues to improve out to 6 hours of MP. Gallinat et $\mathrm{al}^{28}$ have demonstrated that a 2 -hour period of MP following initial static CS may be as effective as continuous MP during the whole preservation period in a porcine
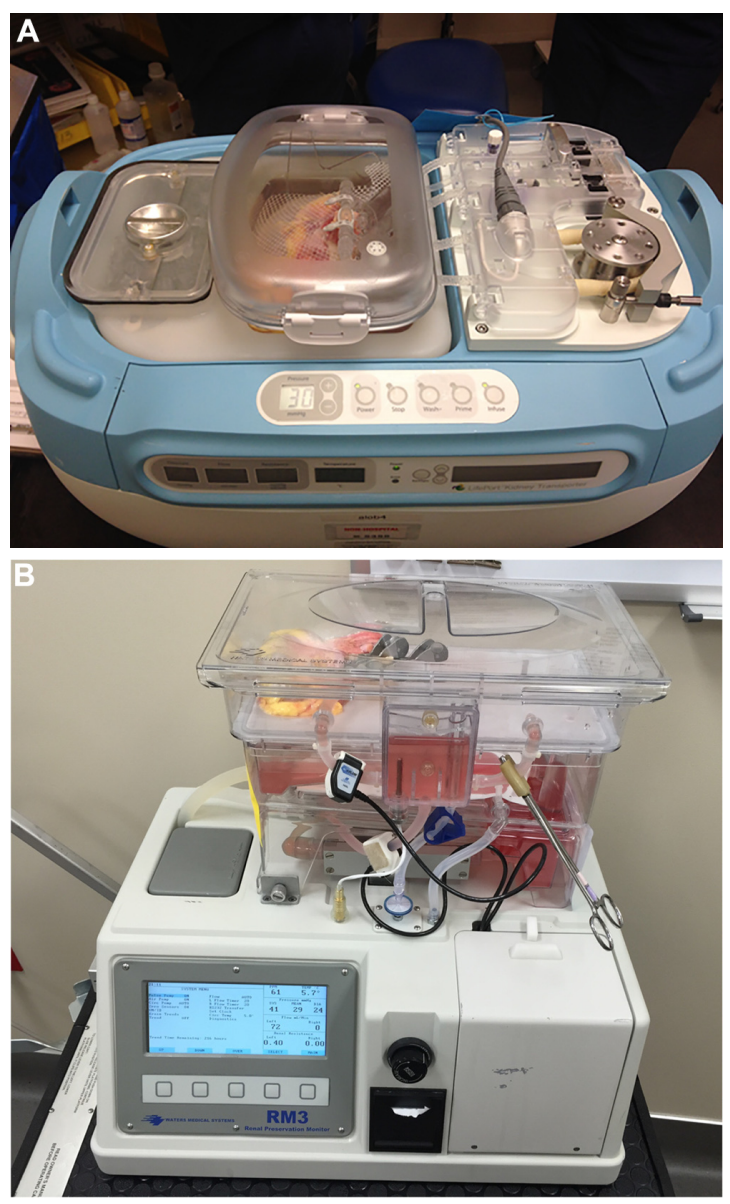

Figure I (A) LifePort Kidney Transporter (Organ Recovery Systems). (B) RM3 (Waters Medical Systems). 
autotransplant model. In a follow-up study, the same group demonstrated that both 1- and 4-hour periods of MP at the end of static CS are similarly effective in improving renal function in an animal model. ${ }^{29}$ Thus, while longer pump times do not appear to be harmful, they may not be necessary to realize the benefits of MP.

\section{Prediction of graft quality with MP}

The MP parameters of flow and resistance are frequently used clinically to determine whether marginal kidneys will be viable for transplantation. Marginal kidneys that demonstrate poor perfusion parameters are often discarded. On the other hand, kidneys that exhibit satisfactory parameters are frequently accepted for transplantation where they may not have been otherwise. In a study of US registry data, Sung et $\mathrm{al}^{30}$ found that pumped kidneys from ECD were significantly less likely to be discarded than those not subjected to MP (29.7\% vs 43.6\%; $P<0.001)$. The least likely kidneys to be discarded were those with terminal resistance of less than $0.18 \mathrm{mmHg} / \mathrm{mL} / \mathrm{min}$ (12.6\% discard rate), while those with resistance $>0.38 \mathrm{mmHg} / \mathrm{mL} / \mathrm{min}$ had a significantly higher discard rate of $53.1 \%(P<0.0001)$. In an analysis of the randomized Eurotransplant trial, elevated resistance was independently associated with DGF and graft failure at 1 year, although the predictive power was low. ${ }^{31}$ Guarrera et $\mathrm{al}^{32}$ reported on a series of eleven SCD kidneys that were transplanted despite poor perfusion parameters (defined as flow less than $80 \mathrm{~mL} / \mathrm{min} / 100 \mathrm{~g}$ and resistance greater than $0.4 \mathrm{mmHg} / \mathrm{mL} / \mathrm{min} / 100 \mathrm{~g}$ ) and found an acceptable DGF rate of $36.3 \%$ given that the majority of organs had cold ischemic times over 20 hours. Both Sonnenday et $\mathrm{al}^{33}$ and Mozes et $\mathrm{al}^{34}$ have also issued reports cautioning against discarding kidneys based on poor perfusion criteria alone. Based on the available evidence, it appears that perfusion parameters alone should not be used to discard kidneys; rather, they should be taken in light of the other available donor data. On the other hand, acceptable MP parameters may form the basis to proceed with transplantation of otherwise marginal kidneys.

In addition to the commonly utilized MP parameters, there is growing interest in the role of perfusate analysis to determine graft viability. In a prospective randomized study, Hall et $\mathrm{al}^{36}$ measured levels of isoenzymes of glutathione S-transferase (GST) in the machine perfusate. The GST protein family comprises cytosolic enzymes that serve a role in detoxifying free radicals. The alpha isoenzyme is released from damaged proximal tubule cells while the pi tubule is released from damaged distal tubules. ${ }^{35}$ Elevated levels of the
pi-GST isoenzyme were independently associated with development of DGF. ${ }^{36}$ In analysis of perfusate biomarkers during the randomized Eurotransplant trial, Moers et $\mathrm{al}^{37}$ determined that GST, $N$-acetyl-beta-D-glucosaminidase, and heart-type fatty acid binding protein were all significantly associated with DGF, but not with primary nonfunction or graft survival. In a preclinical model, Bon et $\mathrm{al}^{38}$ performed metabolomics analysis using nuclear magnetic resonance spectroscopy to determine that changes in the concentration of lactate, choline, and several amino acids exhibited a greater increase in kidneys with poorer outcomes than in kidneys that fared better. Thus it appears that perfusate analysis has the potential to predict DGF that may lead to alterations in posttransplant management; however, perfusate analysis has not yet been shown appropriate for making renal discard decisions.

\section{Active graft reconditioning through MP}

While the process of MP itself is now known to be beneficial in terms of graft function, an exciting avenue for new research is use of the MP circuit to deliver therapeutic substrates that can further augment graft function. Sedigh et al have studied the effects of adding Corline heparin conjugate $(\mathrm{CHC})$ to the machine preservation solution in order to protect the renal vascular endothelium. ${ }^{40}$ The endothelial glycocalyx is an important component of the vascular wall barrier against edema, inflammation, leukocyte adhesion, and platelet adhesion. Damage to the endothelial glycocalyx has been linked to early ischemia reperfusion injury. ${ }^{39}$ When added to the MP solution in a porcine transplant model, Sedigh's group were able to demonstrate binding of $\mathrm{CHC}$ to the vascular endothelium, and have hypothesized that this $\mathrm{CHC}$ has the potential to restore the endothelial glycocalyx and possibly mitigate some of the effects of ischemia reperfusion injury. ${ }^{40}$

In another preclinical model, Snoeijs et $\mathrm{al}^{41}$ evaluated the effects of a water-soluble propofol conjugate on renal function. Propofol has structural similarity to the antioxidant alpha-tocopherol and has antioxidant properties itself. By conjugating propofol to cyclodextrin, Snoeijs et $\mathrm{al}^{41}$ was able to make propofol water soluble and add it to the MP solution in a porcine transplant model. This novel propofol formulation was able to significantly reduce lipid peroxidation and ameliorate the increase in renal vascular resistance seen during the early reperfusion period posttransplantation. This improvement was accompanied by a modest supplement in renal function during the early posttransplant period. 


\section{Oxygenated and normothermic MP techniques}

The majority of current clinical applications of MP utilize a nonoxygenated circuit and continue to employ hypothermia for organ protection. Oxygen consumption even under hypothermic conditions, however, continues at $\sim 5 \%-10 \%$ of that at normal body temperature. ${ }^{42-45}$ This fact forms the primary rationale for investigation into oxygenated techniques of MP. Theoretically, addition of oxygen to the MP circuit could slow or even reverse ATP loss during preservation, thereby ameliorating the process of injury that occurs during storage. This potential benefit must be balanced against the possibility that increasing oxygen levels will lead to increased tissue damage from reactive oxygen species. ${ }^{46-48}$

Gallinat et a ${ }^{49}$ have investigated the utility of oxygenated MP in a porcine model of transplantation from heartbeating donors, which is representative of the majority of kidney donation currently in practice. Kidneys were retrieved from Landrace pigs and immediately placed on either an oxygenated or an anoxic MP circuit for 21 hours, followed by reimplantation into the donor animal with nephrectomy of the contralateral kidney. Vascular resistance at the termination of perfusion was decreased in the oxygenated group; however, there was an increased generation of lipid peroxides with oxygenation of the perfusion circuit. Following transplantation, creatinine clearance was actually significantly better in the anoxic group. This study indicates that for donor kidneys without significant warm ischemic damage, the addition of oxygen to MP is not beneficial, and indeed may prove harmful.

In contrast to the Gallinat's study, Thuillier et $\mathrm{al}^{50}$ investigated oxygenated MP in a porcine model of DCD. The experimental setup in the Thuillier paper is nearly identical to that of the Gallinat study, except that the donor kidneys were subjected to 60 minutes of warm ischemia prior to being placed on the perfusion circuit. Oxygenated MP in this setting resulted in a lower peak serum creatinine and a faster return to normal serum creatinine compared to anoxic perfusion. Three-month follow-up demonstrated decreased interstitial fibrosis and chronic inflammation in the oxygenated kidneys. On the basis of these two studies, oxygenated MP does not appear to have a place in kidneys from standard heartbeating brain dead donors, though it may prove beneficial in improving outcomes for DCD organs that suffer a warm ischemic insult prior to recovery and the institution of perfusion. Theoretically, addition of oxygen to the perfusion circuit could overcome the lack of benefit seen in clinical studies of MP for DCD kidneys. ${ }^{21}$
Normothermic perfusion takes the concept of oxygenation one step further and has several theoretical benefits, including restoration of aerobic metabolism and better assessment of organ viability. ${ }^{51,52}$ Bagul et al ${ }^{53}$ studied the effects of a 2-hour period of normothermic perfusion with autologous blood following a 16-hour CS period in a porcine transplant model. The 2-hour normothermic perfusion period was able to increase the ATP:ADP ratio to a level significantly higher than kidneys subjected to 2 hours of CS, 18 hours of CS, and 18 hours cold MP. In a landmark clinical trial, Nicholson and Hosgood ${ }^{54}$ group applied ex vivo normothermic perfusion with a modified pediatric cardiopulmonary bypass circuit to 18 kidneys from expanded criteria donors. ${ }^{54}$ The perfusate consisted of one unit packed red blood cells to which lactated Ringer's solution, nutrients, and a vasodilator (prostacyclin) were added. They were able to achieve an impressive DGF rate of $5.6 \%$, which is remarkably better than the DGF rate of $19.7 \%$ seen in our study of UNOS data ${ }^{9}$ and $20.8 \%$ seen in the Eurotransplant trial, ${ }^{8}$ despite the fact that these studies included presumably better quality organs from SCD in addition to ECD. Based on these early data, normothermic perfusion appears to be a highly promising modality that may represent the future of kidney preservation.

\section{Conclusion}

After initially being abandoned in favor of static CS in the early days of kidney transplantation, MP has made a significant comeback in the last two decades. Multiple clinical studies including large database analyses and randomized controlled trials are now available demonstrating the ability of MP to improve outcomes following transplantation. Despite this progress, there are still many questions left to answer. We still do not know exactly which subset of kidneys benefit the most from MP and this question is important as cost and logistical concerns will likely prohibit the universal application of MP for the foreseeable future. Assessment of graft viability is also an important area of research, as the parameters of vascular flow and resistance have significant limitations. Perhaps most importantly, future research into perfusate additives, oxygenation, and normothermia hold the potential to allow the current paradigm of organ preservation to one of organ repair and optimization. The concept of ex vivo organ resuscitation is an area of active research and perhaps is the future of all solid organ transplantation. This type of transplant organ management has the potential for increasing preservation times, providing additional organ-specific 
function data to determine suitability for transplantation, organ repair and restoration as well as a new paradigm for organ transportation. Although not fully studied, MP does hold much promise for the future as well as avenues for further research. It has not yet been recommended by use of guidelines by any transplantation society, but its liberal use in the field does appear to continue to grow in many donor service areas. Standard MP is likely just the beginning of a new era of organ management.

\section{Disclosure}

The authors report no conflicts of interest in this work.

\section{References}

1. Mouzas GL. The present status of organ preservation: a review. Postgrad Med J. 1967;43:712-715.

2. Belzer FO, Southard JH. The future of kidney preservation. Transplantation. 1980;30:161-165.

3. Belzer FO, Ashby BS, Gulyassy PF, Powell M. Successful seventeen hour preservation and transplantation of human cadaver kidney. $\mathrm{NEngl}$ J Med. 1968;278:608-610.

4. Schold JD, Kaplan B, Howard RJ, Reed AI, Foley DP, Meier-Kriesche HU. Are we frozen in time? Analysis of the utilization and efficacy of pulsatile perfusion in renal transplantation. Am J Transplant. 2005;5: 1681-1688.

5. Goldstein MJ, Lubezky N, Yushkov Y, Bae C, Guarrera JV. Innovations in organ donation. Mt Sinai J Med. 2012;79:351-364.

6. O'Callaghan JM, Morgan RD, Knight SR, Morris PJ. Systematic review and meta-analysis of hypothermic machine perfusion versus static cold storage of kidney allografts on transplant outcomes. Br J Surg. 2013;100:991-1001.

7. Wight JP, Chilcott JB, Holmes MW, Brewer N. Pulsatile machine perfusion vs cold storage of kidneys for transplantation: a rapid and systematic review. Clin Transplant. 2003;17:293-307.

8. Moers C, Smits JM, Maathuis MH, et al. Machine perfusion or cold storage in deceased-donor kidney transplantation. $N$ Engl J Med. 2009;360:7-19.

9. Cannon RM, Brock GN, Garrison RN, Smith JW, Marvin MR, Franklin GA. To pump or not to pump: a comparison of machine perfusion vs cold storage for deceased donor kidney transplantation. J Am Coll Surg. 2013;216:625-633.

10. Buchanan PM, Lentine KL, Burroughs TE, Schnitzler MA, Salvalaggio PR. Association of lower costs of pulsatile machine perfusion in renal transplantation from expanded criteria donors. Am J Transplant. 2008;8:2391-2401.

11. Treckmann J, Moers C, Smits JM, et al. Machine perfusion versus cold storage for preservation of kidneys from expanded criteria donors after brain death. Transpl Int. 2011;24:548-554.

12. Matsuoka L, Shah T, Aswad S, et al. Pulsatile perfusion reduces the incidence of delayed graft function in expanded criteria donor kidney transplantation. Am J Transplant. 2006;6:1473-1478.

13. Stratta RJ, Moore PS, Farney AC, et al. Influence of pulsatile perfusion preservation on outcomes in kidney transplantation from expanded criteria donors. J Am Coll Surg. 2007;204:873-882.

14. Abboud I, Antoine C, Gaudez F, et al. Pulsatile perfusion preservation for expanded-criteria donors kidneys: impact on delayed graft function rate. Int J Artif Organs. 2011;34:513-518.

15. Plata-Munoz JJ, Muthusamy A, Quiroga I, et al. Impact of pulsatile perfusion on postoperative outcome of kidneys from controlled donors after cardiac death. Transpl Int. 2008;21:899-907.
16. Moustafellos P, Hadjianastassiou V, Roy D, et al. The influence of pulsatile preservation in kidney transplantation from non-heart-beating donors. Transplant Proc. 2007;39:1323-1325.

17. van der Vliet JA, Kievit JK, Hene RJ, Hilbrands LB, Kootstra G. Preservation of non-heart-beating donor kidneys: a clinical prospective randomised case-control study of machine perfusion versus cold storage. Transplant Proc. 2001;33:847.

18. Opelz G, Terasaki PI. Advantage of cold storage over machine perfusion for preservation of cadaver kidneys. Transplantation. 1982;33:64-68.

19. Wight J, Chilcott J, Holmes M, Brewer N. The clinical and cost-effectiveness of pulsatile machine perfusion versus cold storage of kidneys for transplantation retrieved from heart-beating and nonheart-beating donors. Health Technol Assess. 2003;7:1-94.

20. Cantafio AW, Dick AA, Halldorson JB, Bakthavatsalam R, Reyes JD, Perkins JD. Risk stratification of kidneys from donation after cardiac death donors and the utility of machine perfusion. Clin Transplant. 2011;25:E530-E540.

21. Watson CJ, Wells AC, Roberts RJ, et al. Cold machine perfusion versus static cold storage of kidneys donated after cardiac death: a UK multicenter randomized controlled trial. Am J Transplant. 2010;10: 1991-1999.

22. Jochmans I, Moers C, Smits JM, et al. Machine perfusion versus cold storage for the preservation of kidneys donated after cardiac death: a multicenter, randomized, controlled trial. Ann Surg. 2010;252: 756-764.

23. Shah AP, Milgrom DP, Mangus RS, Powelson JA, Goggins WC, Milgrom ML. Comparison of pulsatile perfusion and cold storage for paired kidney allografts. Transplantation. 2008;86:1006-1009.

24. Cannon RM, Brock GN, Garrison RN, Marvin MR, Franklin GA, Davis EG. Machine perfusion: not just for marginal kidney donors. Am Surg. 2015;81:550-556.

25. Wszola M, Kwiatkowski A, Diuwe P, et al. One-year results of a prospective, randomized trial comparing two machine perfusion devices used for kidney preservation. Transpl Int. 2013;26:1088-1096.

26. Ciancio G, Gaynor JJ, Sageshima J, et al. Machine perfusion following static cold storage preservation in kidney transplantation: donormatched pair analysis of the prognostic impact of longer pump time. Transpl Int. 2012;25:34-40.

27. Patel SK, Pankewycz OG, Nader ND, Zachariah M, Kohli R, Laftavi MR. Prognostic utility of hypothermic machine perfusion in deceased donor renal transplantation. Transplant Proc. 2012;44:2207-2212.

28. Gallinat A, Paul A, Efferz P, et al. Hypothermic reconditioning of porcine kidney grafts by short-term preimplantation machine perfusion. Transplantation. 2012;93:787-793.

29. Gallinat A, Efferz P, Paul A, et al. One or 4 h of "in-house" reconditioning by machine perfusion after cold storage improve reperfusion parameters in porcine kidneys. Transpl Int. 2014;27:1214-1219.

30. Sung RS, Christensen LL, Leichtman AB, et al. Determinants of discard of expanded criteria donor kidneys: impact of biopsy and machine perfusion. Am J Transplant. 2008;8:783-792.

31. Jochmans I, Moers C, Smits JM, et al. The prognostic value of renal resistance during hypothermic machine perfusion of deceased donor kidneys. Am J Transplant. 2011;11:2214-2220.

32. Guarrera JV, Goldstein MJ, Samstein B, et al. 'When good kidneys pump badly': outcomes of deceased donor renal allografts with poor pulsatile perfusion characteristics. Transpl Int. 2010;23:444-446.

33. Sonnenday CJ, Cooper M, Kraus E, Gage F, Handley C, Montgomery RA. The hazards of basing acceptance of cadaveric renal allografts on pulsatile perfusion parameters alone. Transplantation. 2003;75: 2029-2033.

34. Mozes MF, Skolek RB, Korf BC. Use of perfusion parameters in predicting outcomes of machine-preserved kidneys. Transplant Proc. 2005;37:350-351.

35. Koyner JL, Vaidya VS, Bennett MR, et al. Urinary biomarkers in the clinical prognosis and early detection of acute kidney injury. Clin J Am Soc Nephrol. 2010;5:2154-2165. 
36. Hall IE, Bhangoo RS, Reese PP, et al. Glutathione S-transferase isoenzymes in perfusate from pumped kidneys are associated with delayed graft function. Am J Transplant. 2014;14:886-896.

37. Moers C, Varnav OC, van HE, et al. The value of machine perfusion perfusate biomarkers for predicting kidney transplant outcome. Transplantation. 2010;90:966-973.

38. Bon D, Billault C, Thuillier R, et al. Analysis of perfusates during hypothermic machine perfusion by NMR spectroscopy: a potential tool for predicting kidney graft outcome. Transplantation. 2014;97:810-816.

39. Seal JB, Gewertz BL. Vascular dysfunction in ischemia-reperfusion injury. Ann Vasc Surg. 2005;19:572-584.

40. Sedigh A, Larsson R, Brannstrom J, et al. Modifying the vessel walls in porcine kidneys during machine perfusion. J Surg Res. 2014;191 455-462.

41. Snoeijs MG, Vaahtera L, de Vries EE, et al. Addition of a water-soluble propofol formulation to preservation solution in experimental kidney transplantation. Transplantation. 2011;92:296-302.

42. Guibert EE, Petrenko AY, Balaban CL, Somov AY, Rodriguez JV, Fuller BJ. Organ preservation: current concepts and new strategies for the next decade. Transfus Med Hemother. 2011;38:125-142.

43. Fuller BJ, Lee CY. Hypothermic perfusion preservation: the future of organ preservation revisited? Cryobiology. 2007;54:129-145.

44. Mitchell T, Saba H, Laakman J, et al. Role of mitochondrial-derived oxidants in renal tubular cell cold-storage injury. Free Radic Biol Med. 2010;49:1273-1282.

45. Hosgood SA, Nicholson HF, Nicholson ML. Oxygenated kidney preservation techniques. Transplantation. 2012;93:455-459.
46. Rauen U, de GH. New insights into the cellular and molecular mechanisms of cold storage injury. J Investig Med. 2004;52:299-309.

47. Thornley TB, Phillips NE, Beaudette-Zlatanova BC, et al. Type 1 IFN mediates cross-talk between innate and adaptive immunity that abrogates transplantation tolerance. J Immunol. 2007;179:6620-6629.

48. Stegemann J, Hirner A, Rauen U, Minor T. Use of a new modified HTK solution for machine preservation of marginal liver grafts. J Surg Res. 2010;160:155-162.

49. Gallinat A, Paul A, Efferz P, et al. Role of oxygenation in hypothermic machine perfusion of kidneys from heart beating donors. Transplantation. 2012;94:809-813.

50. Thuillier R, Allain G, Celhay O, et al. Benefits of active oxygenation during hypothermic machine perfusion of kidneys in a preclinical model of deceased after cardiac death donors. J Surg Res. 2013;184: 1174-1181.

51. Arnaud FG, Khirabadi BS, Fahy GM. Normothermic blood perfusion of isolated rabbit kidneys. II. In vitro evaluation of renal function followed by orthotopic transplantation. ASAIO J. 2000;46:707-718.

52. Hosgood SA, van HE, Nicholson ML. Normothermic machine perfusion of the kidney: better conditioning and repair? Transpl Int. 2015;28:657-664.

53. Bagul A, Hosgood SA, Kaushik M, Kay MD, Waller HL, Nicholson ML. Experimental renal preservation by normothermic resuscitation perfusion with autologous blood. Br J Surg. 2008;95:111-118.

54. Nicholson ML, Hosgood SA. Renal transplantation after ex vivo normothermic perfusion: the first clinical study. Am JTransplant. 2013;13: $1246-1252$.
Transplant Research and Risk Management

\section{Publish your work in this journal}

Transplant Research and Risk Management is an international, peerreviewed open access journal focusing on all aspects of transplantation and risk management to achieve optimal outcomes in the recipient improving survival and quality of life. The journal welcomes submitted papers covering original research, basic science, clinical studies,

\section{Dovepress}

reviews \& evaluations, guidelines, expert opinion and commentary, case reports and extended reports. The manuscript management system is completely online and includes a very quick and fair peer-review system, which is all easy to use. Visit http://www.dovepress.com/ testimonials.php to read real quotes from published authors. 